\title{
Management of ventilator-associated pneumonia in intensive care units: a mixed methods study assessing barriers and facilitators to guideline adherence
}

Nasia Safdar ${ }^{1,2,3^{*}}$, Jackson S Musuuza ${ }^{4}$, Anping Xie ${ }^{5}$, Ann Schoofs Hundt ${ }^{6}$, Matthew Hall ${ }^{7}$, Kenneth Wood ${ }^{8}$ and Pascale Carayon ${ }^{6}$

\begin{abstract}
Background: Guidelines from the Infectious Diseases Society of America/The American Thoracic Society (IDSA/ATS) provide recommendations for diagnosis and treatment of ventilator-associated pneumonia (VAP). However, the mere presence of guidelines is rarely sufficient to promote widespread adoption and uptake. Using the Systems Engineering Initiative for Patient Safety (SEIPS) model framework, we undertook a study to understand barriers and facilitators to the adoption of the IDSA/ATS guidelines.
\end{abstract}

Methods: We conducted surveys and focus group discussions of different health care providers involved in the management of VAP. The setting was medical-surgical ICUs at a tertiary academic hospital and a large multispecialty rural hospital in Wisconsin, USA.

Results: Overall, we found that $55 \%$ of participants indicated that they were aware of the IDSA/ATS guideline. The top ranked barriers to VAP management included: 1) having multiple physician groups managing VAP, 2) variation in VAP management by differing ICU services, 3) physicians and level of training, and 4) renal failure complicating doses of antibiotics.

Facilitators to VAP management included presence of multidisciplinary rounds that include nurses, pharmacist and respiratory therapists, and awareness of the IDSA/ATS guideline. This awareness was associated with receiving effective training on management of VAP, keeping up to date on nosocomial infection literature, and belief that performing a bronchoscopy to diagnose VAP would help with expeditious diagnosis of VAP.

Conclusions: Findings from our study complement existing studies by identifying perceptions of the many different types of healthcare workers in ICU settings. These findings have implications for antibiotic stewardship teams, clinicians, and organizational leaders.

Keywords: Ventilator-associated pneumonia, VAP, Guidelines, Systems Engineering Initiative for Patient Safety, Barriers and facilitators

\footnotetext{
* Correspondence: ns2@medicine.wisc.edu

${ }^{1}$ William S. Middleton Memorial Veterans Hospital, Madison, WI, USA

${ }^{2}$ Department of Medicine, University of Wisconsin School of Medicine and

Public Health, Madison, WI, USA

Full list of author information is available at the end of the article
}

\section{Ciomed Central}

(C) 2016 The Author(s). Open Access This article is distributed under the terms of the Creative Commons Attribution 4.0 International License (http://creativecommons.org/licenses/by/4.0/), which permits unrestricted use, distribution, and reproduction in any medium, provided you give appropriate credit to the original author(s) and the source, provide a link to the Creative Commons license, and indicate if changes were made. The Creative Commons Public Domain Dedication waiver (http://creativecommons.org/publicdomain/zero/1.0/) applies to the data made available in this article, unless otherwise stated. 


\section{Background}

Ventilator-associated pneumonia (VAP) is the most common nosocomial infection in the intensive care unit (ICU), with an incidence ranging from $9 \%$ to as high as $39 \%$ [1-4]. VAP is associated with prolonged hospitalization, health care costs and high mortality rates [5-7]. Healthcare-associated pneumonia, the majority of which in the ICU is VAP, accounts for more than $50 \%$ of the antibiotics prescribed in the ICU and a significant proportion of inappropriate and overprescribed antibiotics [8,9]. Several studies have shown that inappropriate treatment of VAP leads to adverse outcomes [10, 11].

Guidelines from the Infectious Diseases Society of America/The American Thoracic Society (IDSA/ATS) provide recommendations for diagnosis and treatment of VAP [12]. However, it has become clear that the mere presence of a guideline, while necessary, is rarely sufficient to promote widespread adoption and uptake [13-23]. It is unclear as to what extent these guidelines are currently followed in ICUs and what barriers may exist that impede the implementation of these guidelines. A growing body of literature has identified barriers that must be addressed for guidelines to be effectively incorporated into clinical practice $[24,25]$. We used a novel systems engineering framework (Systems Engineering Initiative for Patient Safety-SEIPS) to develop and administer a survey to understand barriers and facilitators to the adoption of the IDSA/ATS guideline.

These barriers may be broadly categorized into the five elements of the work system component of the SEIPS model [26]: 1) characteristics of the guideline to be introduced (the 'tool/technology' element of the work system model), 2) characteristics of the individuals who play a role in adoption and usage of the guideline (the 'individual' element), 3) use of the guideline for changing behavior (the 'task' element), 4) characteristics of the organization in which the change is to occur, such as extent of training (the 'organization' element), and 5) characteristics of the physical environment in which the change is to occur (the 'environment' element) [27]. The objective of this study was to characterize the barriers and facilitators of guideline-concordant care for VAP management.

\section{Methods \\ Settings}

This study was conducted in medical-surgical ICUs at the University of Wisconsin Hospital, a tertiary academic hospital (hospital A) and St. Joseph's Hospital, a large multispecialty rural hospital (hospital B) in the Midwestern US. The medical-surgical ICU at the University of Wisconsin is a 24 bed ICU staffed by board certified intensivists and anesthesiologists. The medical-surgical ICU at St Joseph's hospital is also staffed by trained intensivists. The study was conducted in 2008-2009.

\section{Data collection \\ Focus group methods and development of survey}

To identify barriers and facilitators of managing VAP in ICUs from the providers' perspective, a survey was developed based on literature review and content analysis of data collected from focus groups. Two focus group discussions (FGDs) (one with physicians and one with nurses, respiratory therapists and pharmacists) were conducted at each of the two hospitals. The objective of the FGDs was to identify and discuss issues of VAP management using the SEIPS framework (Fig. 1). Content analysis of focus groups' transcripts identified a total of 193 "unique" comments, which were further classified into 9 themes: (1) communication between providers, (2) difficulty in diagnosing VAP, (3) education related to VAP and

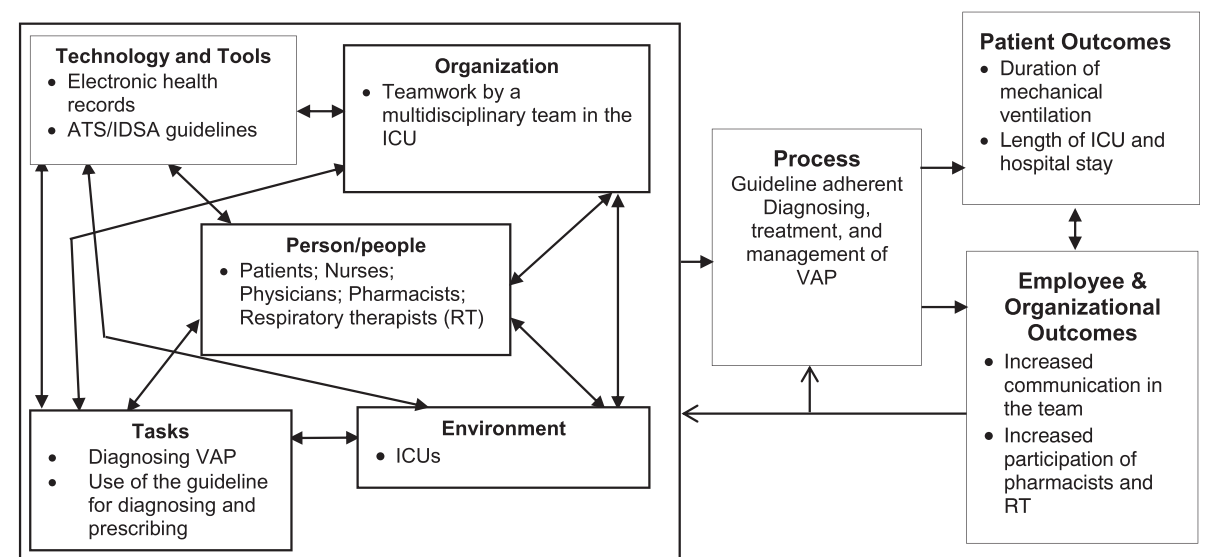

Fig. 1 Adaptation of the SEIPS model to the Management of Ventilator-Associated Pneumonia in Intensive Care Units. The five interacting components of the work system part of the SEIPS model are shown, the process involved and the resulting outcomes 
VAP management, (4) guideline awareness and use, (5) management of the condition, (6) provider responsibilities, (7) technology and its use, (8) use of clinically indicated tests, and (9) variation in practice. Based on the comments and themes identified, a survey was developed and pilot tested on four participants, all of whom were involved in medical management of VAP. They included one physician, one nurse, one respiratory therapist and one pharmacist. Revisions to the content of the questions were made to the survey according to the feedback from pilot testing.

The final survey was adapted to the two hospitals. The version developed for hospital A consisted of five sections. Background had two questions asking the participants if they were aware of the IDSA/ATS guideline for VAP management and to what extent they were willing to follow the guideline. Methods asked participants to indicate to what extent they agree or disagree with 45 statements on VAP management, using a 5-point Likert scale (1 strongly agree, 2 agree, 3 neither agree nor disagree, 4 disagree and 5 strongly disagree). Results asked participants to indicate the frequency with which 17 situations occurred in VAP management. This used a 5-point Likert scale (1 rarely, 2 occasionally, 3 sometimes, 4 fairly often and 5 very often). Discussion had five yes/no questions. These addressed VAP management and diagnosis guidelines and assessed considerations regarding the minibronchoalveolar lavage (mini-BAL) procedure. Conclusion collected demographic information of participants including gender, age, job position, work shift, and average length working for the present employer in the current position.

The survey developed for hospital B similarly had five sections, but a few questions were different from those for hospital A. This was because, in addition to the IDSA/ATS guideline for management of VAP, hospital A also has its own VAP management guidelines that were largely similar to national guidelines but not identical.

\section{Procedure}

The paper survey was distributed to all physicians, nurses, respiratory therapists and pharmacists who practiced in the medical-surgical ICUs at both hospitals. The study was approved by the University of WisconsinMadison and the Marshfield Clinic Institutional Review Boards (IRBs). We obtained informed consent from all participants involved in the study.

\section{Analysis}

Survey data was entered (with verification for accuracy) in an SPSS database. Descriptive statistics were calculated to identify top-ranked barriers and facilitators of VAP management. For each question, the number and percentage of participants who chose each of the available response categories were calculated. If the wording of a question was positive (e.g., pharmacist participation on ICU rounds is beneficial), then participants who chose "agree" and "strongly agree" or "fairly often" and "very often," (when the question was about frequency), considered it as a facilitator; and participants who chose "disagree" and "strongly disagree" or "occasionally" and "rarely" considered it as a barrier. In contrast, if a question was stated in a negative manner (e.g., having multiple groups of physicians manage patients in the ICU complicates VAP guideline use), then participants who chose "agree" and "strongly agree" or "fairly often" and "very often" considered it as a barrier; and participants who chose "disagree" and "strongly disagree" or "occasionally" and "rarely" considered it as a facilitator. Questions were ranked according to the percentage of respondents who considered them as barriers or as facilitators.

Statistical analysis was performed to compare perceptions of participants from different professional groups and to examine the impact of guideline awareness on the perceptions of participants. Three questions designed only for hospital A were excluded from the analysis because they were not applicable to hospital B and 7 questions were excluded from the analysis because they were designed only for physicians and were not applicable to the other healthcare professional groups. Analysis for the remaining questions proceeded as follows. We treated questions that used a 5-point Likert scale (1 rarely, 2 occasionally, 3 sometimes, 4 fairly often and 5 very often) or (1 strongly agree, 2 agree, 3 neither agree nor disagree, 4 disagree and 5 strongly disagree), depending on whether the question was about agreement or frequency, as continuous variables [28]. Because the dependent variables examining the differences between physicians, nurses, respiratory therapists and pharmacists were not normally distributed, we conducted one-way non-parametric ANOVA. When significant differences were identified between different professional groups, post-hoc analysis was performed using the Mann-Whitney test. This test was also used to examine differences between participants who were aware of and who were not aware of the IDSA/ATS guideline for VAP management. The Mann-Whitney test works by ranking all the values from low to high. Therefore, the hypothesis tested in these tests was that means of the ranks in the two comparison groups was zero.

\section{Results}

Surveys were distributed to 115 participants from hospital A and 85 participants in hospital B. A total of 150 participants completed the survey, among whom 87 were from hospital A and 63 participants were from hospital B. The overall response rate was $75 \%$. (hospital A: $75 \%$, hospital B: $74 \%$ ). Table 1 shows the demographics of the participants from the two hospitals. 
Table 1 Demographics of participants

\begin{tabular}{|c|c|c|}
\hline Characteristics & $\begin{array}{l}\text { Hospital A } \\
(N=87)\end{array}$ & $\begin{array}{l}\text { Hospital B } \\
(N=63)\end{array}$ \\
\hline \multicolumn{3}{|l|}{ Gender $^{a}$} \\
\hline Male & $18(21 \%)$ & $20(32 \%)$ \\
\hline Female & 66 (76 \%) & $42(67 \%)$ \\
\hline Missing & $3(3 \%)$ & $1(2 \%)$ \\
\hline \multicolumn{3}{|l|}{$\mathrm{Age}^{\mathrm{a}}$} \\
\hline Less than 25 & $5(6 \%)$ & $2(3 \%)$ \\
\hline Between 25 and 34 & 41 (47 \%) & $23(37 \%)$ \\
\hline Between 35 and 44 & 19 (22 \%) & $14(22 \%)$ \\
\hline Between 45 and 54 & $16(18 \%)$ & $17(27 \%)$ \\
\hline More than 55 & $3(3 \%)$ & $6(10 \%)$ \\
\hline Missing & $3(3 \%)$ & $1(2 \%)$ \\
\hline \multicolumn{3}{|l|}{ Job position ${ }^{\mathrm{a}}$} \\
\hline Nurses & $30(35 \%)$ & $27(43 \%)$ \\
\hline Pharmacists & $22(25 \%)$ & $4(6 \%)$ \\
\hline Respiratory therapists & 34 (39 \%) & $15(24 \%)$ \\
\hline Physicians & $1(1 \%)$ & $17(27 \%)$ \\
\hline \multicolumn{3}{|l|}{ Work shift ${ }^{b}$} \\
\hline $7 \mathrm{am}-7 \mathrm{pm}$ & $40(46 \%)$ & $36(57 \%)$ \\
\hline $7 \mathrm{pm}-7 \mathrm{am}$ & $18(21 \%)$ & $15(24 \%)$ \\
\hline $7 \mathrm{am}-3 \mathrm{pm}$ & 19 (22 \%) & $13(21 \%)$ \\
\hline $3 p m-11 p m$ & $8(9 \%)$ & $10(16 \%)$ \\
\hline 11 pm - 7 am & $7(8 \%)$ & $5(8 \%)$ \\
\hline $\begin{array}{l}\text { Average length working for the present } \\
\text { employer }\end{array}$ & 10.5 years & 9.2 years \\
\hline Average length working in the current position & 8.8 years & 8.8 years \\
\hline
\end{tabular}

${ }^{a}$ Total percentage does not sum to $100 \%$ because of rounding

${ }^{\mathrm{b}}$ Total percentage exceeds $100 \%$ because more than one option could be chosen

\section{Barriers and facilitators}

The top ranked barriers to VAP management identified in this study included (Table 2): 1) having multiple physician groups managing VAP, 2) variation in VAP management by differing ICU services, 3) physicians and level of training, and 4) renal failure complicating doses of antibiotics.

Facilitators to VAP management (Table 3) included presence of multidisciplinary rounds that include nurses, pharmacist and respiratory therapists, and awareness of the IDSA/ATS guideline. This awareness was associated with receiving effective training on management of VAP, keeping up to date on nosocomial infection literature, and belief that performing a bronchoscopy to diagnose VAP would help with expeditious diagnosis of VAP.

Table 4 shows the number of participants from each professional group who were aware of and who were not aware of the IDSA/ATS guideline for VAP management. Overall, $55 \%$ of participants indicated that they were aware of the IDSA/ATS guideline for VAP management.

The next set of analyses shows results of the one-way non-parametric ANOVA and Mann-Whitney tests applied to items classified within each of nine themes identified from the content analysis of focus groups. The category with a smaller mean rank for a positively worded questions indicates that the group did better on that item than the comparison group, while a smaller mean rank on a negatively worded question indicates that the group did worse than the comparison.

None of the questions classified under three of the nine themes-variation in practice, communication between providers, and technology and its use differed significantly between participants who were aware of the guideline and those who were not (results not presented). For professional groups, only statistically significant (Bonferroni corrected) pairwise comparisons are presented in the paper and are summarized in Table 5 (Online supplemental material).

Compared to other professional groups, a higher proportion $(71 \%)$ of respiratory therapists agreed that more clinically useful specimens are collected when mini-BALs are performed (followed by physicians (61 \%), nurses (45\%) and then pharmacists (25\%), $(p=0.01)$.

\section{Discussion}

VAP accounts for a major proportion of anti-infective use in the ICU. Recent data indicate that antibiotic use is significantly higher in ICU patients compared with non-ICU patients for most antimicrobials [29] Optimizing management of VAP is clearly essential yet remains variable $[30,31]$ and is associated with suboptimal prescribing practices [32].

Table 2 List of the top-ranked barriers to VAP management

\begin{tabular}{|c|c|c|}
\hline Barriers & Percent & Response category \\
\hline Having multiple physician groups manage patients in the ICU complicates VAP guideline use. & $67.3 \%$ & Agree \& strongly agree \\
\hline There is variation in VAP management depending on what service the ICU patient is on. & $64.3 \%$ & Agree \& strongly agree \\
\hline ICU patients with renal failure complicate decision-making when ordering antibiotics. & $57.4 \%$ & Agree \& strongly agree \\
\hline $\begin{array}{l}\text { Within physician service there is variation in VAP management depending on who is the VAP patient's } \\
\text { attending physician. }\end{array}$ & $56.8 \%$ & Agree \& strongly agree \\
\hline There is variation in VAP management between attending physicians and house staff in the ICU. & $52.6 \%$ & Agree \& strongly agree \\
\hline
\end{tabular}


Table 3 List of the top-ranked facilitators to VAP management

\begin{tabular}{lll}
\hline Facilitators & Percent & Response category \\
\hline Pharmacist participation on ICU rounds is beneficial. & $98.60 \%$ & Agree \& strongly agree \\
Nurse participation on ICU rounds is beneficial. & $98.00 \%$ & Agree \& strongly agree \\
Respiratory therapist participation on ICU rounds is beneficial. & $96.70 \%$ & Agree \& strongly agree \\
I can readily access orders that are written for my ICU patients. & $92.60 \%$ & Agree \& strongly agree \\
Respiratory therapy services are readily available on my ICU. & $92.30 \%$ & Fairly often \& very often \\
Multidisciplinary management of patients occurs on my ICU. & $91.90 \%$ & Agree \& strongly agree \\
Nurses consistently participate on ICU patient rounds. & $90.30 \%$ & Fairly often \& very often \\
Physicians are receptive to pharmacist input in ICU patient care. & $89.70 \%$ & Agree \& strongly agree \\
Pharmacists on my ICU effectively monitor antibiotic use. & $89.30 \%$ & Agree \& strongly agree \\
Pharmacist participation in ICU patient management promotes appropriate antibiotic ordering. & $89.00 \%$ & Agree \& strongly agree \\
Pharmacists consistently participate on ICU patient rounds. & $88.10 \%$ & Fairly often \& very often \\
It is effective to have pharmacists help determine the appropriateness of ICU antibiotic de-escalation. & $87.70 \%$ & Agree \& strongly agree \\
I can readily access the information I want on my ICU patients in the EMR. & $86.90 \%$ & Agree \& strongly agree \\
Using VAP management guidelines helps me to manage VAP patients in the ICU. & $86.70 \%$ & Agree \& strongly agree \\
Pharmacy intervention in antibiotic ordering leads to effective ICU VAP management. & $86.30 \%$ & Agree \& strongly agree \\
Respiratory therapists consistently participate on ICU patient rounds. & $83.20 \%$ & Fairly often \& very often \\
I can appropriately manage ICU patients with VAP. & $83.10 \%$ & Agree \& strongly agree \\
VAP management guidelines interfere with my ability to manage my ICU patients. & $82.30 \%$ & Occasionally \& rarely \\
\hline
\end{tabular}

Antibiotic treatment guidelines have emerged as a potentially effective means of avoiding unnecessary antibiotic administration, increasing the effectiveness of prescribed antibiotics, and reducing antimicrobial resistance as well [33].

In our study, we attempted to understand the adoption and uptake of a national VAP diagnosis and management guideline [12]. Overall, we found that $55 \%$ of participants indicated that they were aware of the IDSA/ATS guideline. The top ranked barriers to VAP management included: 1) having multiple physician groups managing VAP, 2) variation in VAP management by differing ICU services, 3) physicians and level of training, and 4) renal failure complicating doses of antibiotics. Changes in renal clearance following renal failure make it difficult to establish precise antimicrobial dosing [34].

One of the top barriers to VAP management, having multiple physician groups managing VAP may be more likely to lead to poor patient outcomes particularly because of the increased likelihood of communication errors in the presence of multiple providers $[35,36]$.

Most respondents felt that nurse, pharmacist, and respiratory therapy participation in rounds was beneficial for VAP management. This finding further emphasizes the need for multidisciplinary rounds which have been associated with improved patient outcomes such as reduced mortality [37, 38] and reduced length of hospital stay [39].

Participants who were aware of the guideline also believed that they received effective training on management and kept up to date on nosocomial infection literature. However, they were less likely to believe that ICU respiratory therapists are capable of performing mini-BALs.

Compared to nurses, more pharmacists believed that there was variation in VAP management. This is not surprising because most of the variation in VAP management occurs in antibiotic use and pharmacists have a key role in that decision-making process. Awareness of the guideline was also more likely to be associated with

Table 4 Proportion of participants aware of the VAP management guideline per job category

\begin{tabular}{|c|c|c|c|c|}
\hline & \multicolumn{3}{|c|}{ Aware of IDSA/ATS guideline for VAP management } & \multirow[t]{2}{*}{ Total } \\
\hline & Yes & No & Missing & \\
\hline Physicians & 8 & 10 & 0 & 18 \\
\hline Nurses & 30 & 22 & 5 & 57 \\
\hline Respiratory therapists & 22 & 17 & 10 & 49 \\
\hline Pharmacists & 23 & 3 & 0 & 26 \\
\hline Total & 83 & 52 & 15 & 150 \\
\hline
\end{tabular}


Table 5 Comparisons of professional groups' perceptions and beliefs about various items related to VAP management

\begin{tabular}{ll}
\hline Theme & Item \\
\hline Communication between & $\begin{array}{l}\text { They would benefit by receiving clinical progress } \\
\text { providers } \\
\text { reports feedback on VAP patients after they are } \\
\text { discharged from the ICU } \\
\text { Could more readily access information on ICU } \\
\text { patients from the EMR }\end{array}$
\end{tabular}

Difficulty in diagnosing VAP Being able to perform a bronchoscopy in the ICU helps the physician to expeditiously diagnose VAP

Education related to VAP and VAP management

Received effective training on VAP management

Kept up-to-date on nosocomial infection literature

Could appropriately manage ICU patients with VAP

Believe that they could easily interpret quantitative culture results related to VAP (applicable to physicians only)

Believe that they could accurately diagnose ICU patients with VAP (applicable to physicians only) Kept up-to-date on nosocomial infection literature

Guideline awareness and use ICU VAP management order sets would facilitate VAP management

VAP management guidelines interfere with their ability to manage my ICU patients

Management of the condition

Provider responsibilities

Technology and its use

Use of clinically indicated tests
Having nurses float between ICUs interferes with standardized VAP patient management

Physicians are receptive to respiratory therapist input in ICU patient care

Physicians are receptive to pharmacists' input in ICU patient care

ICU patients with renal failure complicate decision-making when ordering antibiotics

It is effective to have pharmacists help determine the appropriateness of ICU antibiotic de-escalation

Attending physicians should be responsible for educating house staff on VAP management guidelines

Respiratory therapy does not respond promptly to mini-BAL orders for ICU patients with suspected VAP

Pharmacy intervention in antibiotic ordering leads to effective ICU VAP management

Multidisciplinary management of patients occurs on their ICU

Pharmacists on their ICU effectively monitor antibiotic use

Having an electronic medical record (EMR) reduces the time necessary to diagnose VAP in the ICU

ICU respiratory therapists are capable of performing mini-BALs

ICU respiratory therapists are capable of performing mini-BALs

More clinically useful specimens are collected when mini-BALs are performed

\begin{tabular}{ll} 
Mean Rank & $P$-Value \\
\hline Physicians vs. respiratory therapists, 43.1 vs 72.4 & 0.03 \\
Physicians vs. pharmacists, 43.1 vs 85.2 & 0.02 \\
$\begin{array}{l}\text { Respiratory therapists vs. nurses, } \\
=62.8 \text { vs } 85.0\end{array}$ & 0.02 \\
$\begin{array}{l}\text { Physicians aware of the guideline vs. } \\
\text { those not aware of it, } 57.4 \text { vs } 68.7\end{array}$ & 0.05 \\
$\begin{array}{l}\text { Participants aware of the guideline vs. those } \\
\text { not aware of it, } 56.7 \text { vs } 83.6\end{array}$ & $<.01$
\end{tabular}

Participants aware of the guideline vs. those $\quad<.001$ not aware of it, 54.73 vs 85.81

Participants aware of the guideline vs. those $\quad 0.01$ not aware of it, 58.14 vs 71.35

Participants aware of the guideline vs. those $\quad 0.01$ not aware of it, 55.92 vs 72.17

Participants aware of the guideline vs. those not aware of it, 41.81 vs. 53.16

Pharmacists vs. nurses, 58.8 vs 83.9

Pharmacists vs. respiratory therapists, 51.5 vs $88.5<.01$

Physicians vs. respiratory therapists, 54.6 vs $88.5<.01$

Respiratory therapists vs. pharmacists, 44.0 vs $72.1<.01$

*Participants aware of the guideline vs. those $\quad<.001$ not aware of it, 70.1 vs 57.5

Physicians vs. respiratory therapists, 56.0 vs $87.9<.01$

Physicians vs. respiratory therapists, 52.3 vs 79.5

Physicians vs. pharmacists, 35.6 vs 70.7

Physicians vs. respiratory therapists, 35.6 vs 79.2

Nurses respiratory therapists, 56.1 vs 79.2

Participants aware of the guideline vs. those $<.001$ not aware of it, 57.8 vs 73.2

Pharmacists vs. respiratory therapists, 49.9 vs $82.5<.01$

Participants aware of the guideline vs. those $\quad 0.04$ not aware of it, 61.6 vs 74.5

Participants aware of the guideline vs. those $\quad 0.05$ not aware of it, 51.54 vs 41.3

Pharmacists vs. respiratory therapists, 50.5 vs 86.2, <.01

Nurses vs. respiratory therapists, 67.8 vs $86.2, \quad 0.04$

Pharmacists vs. respiratory therapists, 63.8 vs 88.10 .04

Pharmacists vs. respiratory therapists, 50.1 vs $82.9<.01$

Physicians vs. nurses, 42.6 vs $75.9 \quad 0.04$

Physicians vs. pharmacists, 42.6 vs $76.8 \quad 0.02$

*Participants aware of the guideline vs. those 0.03 not aware of it, 63.8

Respiratory therapists vs. pharmacists, 49.3 vs $84.2 \quad<.01$

Respiratory therapists vs. physicians, 49.3 vs $91.1<.01$ 
Table 5 Comparisons of professional groups' perceptions and beliefs about various items related to VAP management (Continued)

\begin{tabular}{|c|c|c|c|}
\hline \multirow[t]{8}{*}{ Variation in practice } & $\begin{array}{l}\text { There is variation in VAP management depending } \\
\text { on what service the ICU patient was on }\end{array}$ & Pharmacists vs. respiratory therapists, 47.9 vs 84.3 & $<.01$ \\
\hline & $\begin{array}{l}\text { There is variation in VAP management depending } \\
\text { on who the VAP patient's attending physician was }\end{array}$ & Pharmacists vs. respiratory therapists, 52.3 vs 79.8 & $<.01$ \\
\hline & \multirow{2}{*}{$\begin{array}{l}\text { There is variation in VAP management between } \\
\text { attending physicians and house staff in the ICU }\end{array}$} & Pharmacists vs. respiratory therapists44.2 vs 75.5 & $<.01$ \\
\hline & & Pharmacists vs. nurses, 44.2 vs 76.0 & $<.01$ \\
\hline & \multirow{4}{*}{$\begin{array}{l}\text { Antibiotic ordering practices vary between house } \\
\text { staff and attending physicians in the ICU }\end{array}$} & Respiratory therapists vs. pharmacists, 33.7 vs 63.2 & \multirow[t]{2}{*}{0.02} \\
\hline & & Respiratory therapists vs. physicians, 33.7 vs 64.3 & \\
\hline & & Respiratory therapists vs. physicians, 33.7 vs 64.3 & 0.03 \\
\hline & & Nurses vs. pharmacists, 45.0 vs 63.2 & 0.04 \\
\hline
\end{tabular}

Note: Only statistically significant (Bonferroni corrected) pairwise comparisons are presented in this table

A 5-point Likert scale used was as follows:1 strongly agree, 2 agree, 3 neither agree nor disagree, 4 disagree and 5 strongly disagree or 1 rarely, 2 occasionally,

3 sometimes, 4 fairly often and 5 very often. Therefore, a professional group with a smaller rank was more likely to believe or report the stated item than the professional group with a larger mean rank. The opposite is true for items with *

$E M R$ electronic medical record, VAP ventilator-associated pneumonia, ICU intensive care unit, mini-BAL mini-bronchoalveolar lavage

belief that performing a bronchoscopy to diagnose VAP would help with expeditious diagnosis of VAP.

Other studies have shown that implementing the IDSA/ATS guideline by customizing it into center-specific guidelines was associated with increased adherence to guideline diagnostic criteria for nosocomial pneumonia and guideline-concordant empiric antibiotics [40, 41]. Our findings complement these existing studies by identifying perceptions of the many different types of healthcare workers (HCWs) in ICU settings.

Our study has limitations. Our survey was limited to two institutions in Wisconsin and thus may limit generalizability of our findings. We did not measure guideline adherence or correlate it with outcomes. A recent study found that guideline-adherent initial intravenous antibiotic therapy led to better patient outcomes and was less expensive than non-guideline adherent therapy [42]. However, other studies have shown that guideline adherent care alone did not necessarily improve patient outcomes such as the frequent need for mechanical ventilation and all-cause 30 day mortality [43, 44]. We did not collect further data on the demographics of the respondents to allow comparisons between attendings and trainees for example. Knowledge of the guidelines might be different between these categories. We had less physician participation than other types of HCWs. Finally, as with any survey-based studies, we also cannot rule out the possibility of variability in question interpretation $[45,46]$.

These limitations notwithstanding, our findings have implications for antibiotic stewardship teams, clinicians, and organizational leaders.

\section{Conclusion}

About half of the respondents reported that they were aware of the IDSA/ATS guideline. Awareness of guidelines was associated with a belief that respondents received effective training on management and kept up to date on nosocomial infection literature. The top ranked barriers to VAP management included having multiple physician groups managing VAP, variation in VAP management by differing ICU services, physicians and level of training and renal failure complicating doses of antibiotics. Nurse, pharmacist and respiratory therapy participation in rounds was viewed as beneficial to VAP management by most respondents. Future studies should rigorously examine the impact of guideline adherence for VAP management to clinical patient outcomes and assess process measures to gauge degree and success of guideline implementation.

\section{Abbreviations}

ANOVA, Analysis of variance; ATS, American Thoracic Society; HCWs, healthcare workers; ICU, intensive care unit; IDSA, Infectious Diseases Society of America; mini-BAL, mini-bronchoalveolar lavage; SEIPS, Systems Engineering Initiative for Patient Safety; VAP, ventilator-associated pneumonia

\section{Acknowledgements}

We acknowledge all the individuals that participated in the study as respondents.

\section{Funding}

The project described was supported by the Clinical and Translational Science Award (CTSA) program, through the NIH National Center for Advancing Translational Sciences (NCATS), grant UL1TR000427. NS is supported by a United States Department of Veterans Affairs MERIT award. The content is solely the responsibility of the authors and does not necessarily represent the official views of the $\mathrm{NIH}$ or the Department of Veterans Affairs. There are no conflicts of interest for any of the authors.

Availability of data and materials

The data on which conclusions are based is available from authors upon request.

\section{Authors' contributions}

NS: obtained funding and led the study JSM: participated in drafting of the manuscript and analysis. AX: critical editing of the manuscript and participation in study activities. AH critical editing of the manuscript and participation in study activities. MH: critical editing of the manuscript and participation in study activities. KEW: critical editing of the manuscript and participation in study activities. PC: critical editing of the manuscript and participation in study activities. All authors read and approved the manuscript. 


\section{Authors' information}

NS: Has an MD and a PhD degree. She is the Associate Chief of Staff for Research and staff physician in infectious diseases at the William S. Middleton VA Medical Center, Madison, Wisconsin, USA. She is also an Associate Professor in the Department of Medicine, University of Wisconsin-Madison, WI, USA. JSM: Holds a medical degree, a master of Public Health and a master of science in Population Health Sciences. He is currently a PhD candidate in Clinical Epidemiology at the University of Wisconsin, Madison, USA. AX: Has a PhD in Industrial and Systems Engineering. He is currently an Assistant Professor at Armstrong Institute for Patient Safety and Quality, Johns Hopkins University School of Medicine, Baltimore, Maryland, USA. ASH: Has a PhD in Industrial and Systems Engineering. She is currently the Associate Director for Education at the Center for Quality and Productivity Improvement, University of Wisconsin-Madison, Madison, WI, USA. MH: Is an Infectious disease physician at the Department of Infectious Medicine, Marshfield Clinic, Marshfield, WI, USA.

KEW: Professor of Medicine at the R Adams Cowley Shock Trauma Center, University of Maryland School of Medicine, Baltimore, MD, USA. PC: Has a PhD in Industrial and Systems Engineering. She is a Procter \& Gamble Bascom Professor in Total Quality, Industrial and Systems Engineering. She is also the Director, Center for Quality and Productivity Improvement, University of Wisconsin-Madison, Madison, WI, USA.

\section{Competing interests}

Investigators will receive only normal scholarly gains from taking part in this study. The authors declare no competing interests.

\section{Ethics approval and consent to participate}

The study was approved by the University of Wisconsin-Madison and the Marshfield Clinic Institutional Review Boards (IRBs). We obtained informed consent from all participants involved in the study.

\section{Author details}

${ }^{1}$ William S. Middleton Memorial Veterans Hospital, Madison, WI, USA.

${ }^{2}$ Department of Medicine, University of Wisconsin School of Medicine and Public Health, Madison, WI, USA. ${ }^{3}$ Department of Infectious Disease, University of Wisconsin Hospital and Clinics, Madison, WI, USA. ${ }^{4}$ Institute for Clinical and Translational Research, University of Wisconsin, Madison, WI, USA. ${ }^{5}$ Armstrong Institute for Patient Safety and Quality, Johns Hopkins University School of Medicine, Baltimore, MD, USA. ${ }^{6}$ Center for Quality and Productivity Improvement, University of Wisconsin-Madison, Madison, WI, USA. ${ }^{7}$ Department of Infectious Medicine, Marshfield Clinic, Marshfield, WI, USA. ${ }^{8} \mathrm{R}$ Adams Cowley Shock Trauma Center, University of Maryland School of Medicine, Baltimore, MD, USA.

Received: 27 October 2015 Accepted: 24 June 2016

Published online: 22 July 2016

\section{References}

1. Mitharwal SM, Yaddanapudi S, Bhardwaj N, Gautam V, Biswal M, Yaddanapudi L. Intensive care unit-acquired infections in a tertiary care hospital: An epidemiologic survey and influence on patient outcomes. Am J Infect Control. 2016:44(7):e113-e117.

2. Bor C, Demirag K, Okcu O, Cankayali I, Uyar M. Ventilator-associated pneumonia in critically ill patients with intensive antibiotic usage. Pak J Med Sci. 2015;31(6):1441-6.

3. Rosenthal VD, Maki DG, Jamulitrat S, Medeiros EA, Todi SK, Gomez DY, et al. International Nosocomial Infection Control Consortium (INICC) report, data summary for 2003-2008, issued June 2009. Am J Infect Control. 2010;38(2):95-104. e2.

4. Edwards JR, Peterson KD, Mu Y, Banerjee S, Allen-Bridson K, Morrell G, et al. National Healthcare Safety Network (NHSN) report: data summary for 2006 through 2008, issued December 2009. Am J Infect Control. 2009; 37(10):783-805.

5. Shorr AF, Zilberberg MD, Kollef M. Cost-effectiveness analysis of a silvercoated endotracheal tube to reduce the incidence of ventilator-associated pneumonia. Infect Control Hosp Epidemiol. 2009;30(8):759-63.

6. Kollef KE, Schramm GE, Wills AR, Reichley RM, Micek ST, Kollef MH. Predictors of 30-day mortality and hospital costs in patients with ventilator-associated pneumonia attributed to potentially antibiotic-resistant gram-negative bacteria. Chest. 2008;134(2):281-7.
7. Safdar N, Dezfulian C, Collard HR, Saint S. Clinical and economic consequences of ventilator-associated pneumonia: a systematic review. Crit Care Med. 2005;33(10):2184-93.

8. Glowacki RC, Schwartz DN, Itokazu GS, Wisniewski MF, Kieszkowski P, Weinstein RA. Antibiotic combinations with redundant antimicrobial spectra: clinical epidemiology and pilot intervention of computer-assisted surveillance. Clin Infect Dis. 2003;37(1):59-64

9. Koenig SM, Truwit JD. Ventilator-associated pneumonia: diagnosis, treatment, and prevention. Clin Microbiol Rev. 2006;19(4):637-57.

10. Micek ST, Heuring TJ, Hollands JM, Shah RA, Kollef MH. Optimizing antibiotic treatment for ventilator-associated pneumonia. Pharmacotherapy. 2006;26(2):204-13.

11. Luna CM, Aruj P, Niederman MS, Garzon J, Violi D, Prignoni A, et al. Appropriateness and delay to initiate therapy in ventilator-associated pneumonia. Eur Respir J. 2006:27(1):158-64.

12. Guidelines for the management of adults with hospital-acquired, ventilator-associated, and healthcare-associated pneumonia. Am J Respir Crit Care Med 2005;171(4):388-416.

13. Ilan R, Fowler RA, Geerts R, Pinto R, Sibbald WJ, Martin CM. Knowledge translation in critical care: factors associated with prescription of commonly recommended best practices for critically ill patients. Crit Care Med. 2007;35(7):1696-702

14. Jain MK, Heyland D, Dhaliwal R, Day AG, Drover J, Keefe L, et al. Dissemination of the Canadian clinical practice guidelines for nutrition support: results of a cluster randomized controlled trial. Crit Care Med. 2006;34(9):2362-9.

15. Hagedorn H, Hogan M, Smith JL, Bowman C, Curran GM, Espadas D, et al. Lessons learned about implementing research evidence into clinical practice. Experiences from VA QUERI. J Gen Intern Med. 2006;21 Suppl 2:S21-4.

16. Stetler CB, Legro MW, Rycroft-Malone J, Bowman C, Curran G, Guihan M, et al. Role of "external facilitation" in implementation of research findings: a qualitative evaluation of facilitation experiences in the Veterans Health Administration. Implement Sci. 2006;1:23.

17. Stetler CB, Legro MW, Wallace CM, Bowman C, Guihan M, Hagedorn H, et al The role of formative evaluation in implementation research and the QUERI experience. J Gen Intern Med. 2006;21 Suppl 2:S1-8.

18. Rello J, Lorente C, Bodi M, Diaz E, Ricart M, Kollef MH. Why do physicians not follow evidence-based guidelines for preventing ventilator-associated pneumonia?: a survey based on the opinions of an international panel of intensivists. Chest. 2002;122(2):656-61.

19. Finkelstein JA, Lozano P, Shulruff R, Inui TS, Soumerai SB, Ng M, et al. Self-reported physician practices for children with asthma: are national guidelines followed? Pediatrics. 2000;106(4 Suppl):886-96.

20. Bishop PB, Wing PC. Knowledge transfer in family physicians managing patients with acute low back pain: a prospective randomized control trial. Spine J. 2006;6(3):282-8.

21. Vernacchio L, Vezina RM, Mitchell AA. Knowledge and practices relating to the 2004 acute otitis media clinical practice guideline: a survey of practicing physicians. Pediatr Infect Dis J. 2006;25(5):385-9.

22. Vernacchio L, Vezina RM, Mitchell AA. Management of acute otitis media by primary care physicians: trends since the release of the 2004 American Academy of Pediatrics/American Academy of Family Physicians clinical practice guideline. Pediatrics. 2007;120(2):281-7.

23. Cason CL, Tyner T, Saunders S, Broome L. Nurses' implementation of guidelines for ventilator-associated pneumonia from the Centers for Disease Control and Prevention. Am J Crit Care. 2007;16(1):28-36. discussion 7; quiz 8.

24. Carayon P, Gurses AP, Hundt AS, Ayoub P, Alvarado CJ. Performance obstacles and facilitators of healthcare providers. In: Korunka C, Hoffmann P, editors. Change and Quality in Human Service Work, vol. 4. Munchen: Hampp Publishers; 2005. p. 257-76

25. Erhardt LR. Barriers to effective implementation of guideline recommendations. Am J Med. 2005;118(Suppl 12A):36-41.

26. Carayon P, Schoofs Hundt A, Karsh BT, Gurses AP, Alvarado CJ, Smith M, et al. Work system design for patient safety: the SEIPS model. Qual Saf Health Care. 2006;15 Suppl 1:150-8.

27. Cabana MD, Rand CS, Powe NR, Wu AW, Wilson MH, Abboud PA, et al. Why don't physicians follow clinical practice guidelines? A framework for improvement. Jama. 1999;282(15):1458-65.

28. Carifio J, Perla R. Ten common misunderstandings, misconceptions, persistent myths and urban legends about Likert scales and Likert response formats and their antidotes. J Soc Sci. 2007;3:106-16.

29. McGowan Jr J, Tenover F. Antimicrobial resistance in the intensive care unit: impact of new patterns. Int J Clin Pract Suppl. 1998;95:14-22. 
30. Fowler RA, Flavin KE, Barr J, Weinacker AB, Parsonnet J, Gould MK. Variability in antibiotic prescribing patterns and outcomes in patients with clinically suspected ventilator-associated pneumonia. Chest. 2003;123(3):835-44.

31. Kollef MH, Morrow LE, Niederman MS, Leeper KV, Anzueto A, Benz-Scott L, et al. Clinical characteristics and treatment patterns among patients with ventilator-associated pneumonia. Chest. 2006;129(5):1210-8.

32. Dupont H, Mentec H, Sollet JP, Bleichner G. Impact of appropriateness of initial antibiotic therapy on the outcome of ventilator-associated pneumonia. Intensive Care Med. 2001;27(2):355-62.

33. Kollef $\mathrm{MH}$, Fraser $\mathrm{VJ}$. Antibiotic resistance in the intensive care unit. Ann Intern Med. 2001;134(4):298-314.

34. Kumar A, Singh NP. Antimicrobial dosing in critically ill patients with sepsisinduced acute kidney injury. Indian J Crit Care Med. 2015;19(2):99-108.

35. Streitenberger K, Breen-Reid K, Harris C. Handoffs in care-can we make them safer? Pediatr Clin North Am. 2006;53(6):1185-95.

36. The Joint Commission announces the 2006 National Patient Safety Goals and requirements. Jt Comm Perspect 2005;25(7):1-10.

37. McHugh MD. Daily multidisciplinary team rounds associated with reduced 30-day mortality in medical intensive care unit patients. Evid Based Nurs. 2010;13(3):91-2

38. Kim MM, Barnato AE, Angus DC, Fleisher LA, Fleisher LF, Kahn JM. The effect of multidisciplinary care teams on intensive care unit mortality. Arch Intern Med. 2010;170(4):369-76

39. Dutton RP, Cooper C, Jones A, Leone S, Kramer ME, Scalea TM. Daily multidisciplinary rounds shorten length of stay for trauma patients. J Trauma. 2003:55(5):913-9.

40. Mangino JE, Peyrani P, Ford KD, Kett DH, Zervos MJ, Welch VL, et al. Development and implementation of a performance improvement project in adult intensive care units: overview of the Improving Medicine Through Pathway Assessment of Critical Therapy in Hospital-Acquired Pneumonia (IMPACT-HAP) study. Crit Care. 2011;15(1):R38.

41. Madaras-Kelly KJ, Remington RE, Sloan KL, Fan VS. Guideline-based antibiotics and mortality in healthcare-associated pneumonia. J Gen Intern Med. 2012;27(7):845-52.

42. Wilke M, Grube RF, Bodmann KF. Guideline-adherent initial intravenous antibiotic therapy for hospital-acquired/ventilator-associated pneumonia is clinically superior, saves lives and is cheaper than non guideline adherent therapy. Eur J Med Res. 2011;16(7):315-23.

43. Grenier C, Pépin J, Nault V, Howson J, Fournier X, Poirier MS, et al. Impact of guideline-consistent therapy on outcome of patients with healthcareassociated and community-acquired pneumonia. J Antimicrob Chemother. 2011:66(7):1617-24.

44. Becher RD, Hoth JJ, Rebo JJ, Kendall JL, Miller PR. Locally derived versus guideline-based approach to treatment of hospital-acquired pneumonia in the trauma intensive care unit. Surg Infect (Larchmt). 2012;13(6):352-9.

45. Furnham A. Response bias, social desirability and dissimulation. Personal Individ Differ. 1986;7(3):385-400.

46. Bowling A. Mode of questionnaire administration can have serious effects on data quality. J Public Health (Oxf). 2005;27(3):281-91.

\section{Submit your next manuscript to BioMed Central and we will help you at every step:}

- We accept pre-submission inquiries

- Our selector tool helps you to find the most relevant journal

- We provide round the clock customer support

- Convenient online submission

- Thorough peer review

- Inclusion in PubMed and all major indexing services

- Maximum visibility for your research

Submit your manuscript at www.biomedcentral.com/submit

) Biomed Central 